\title{
Short communication: Association of foot and leg conformation and body weight with claw disorders in Spanish Holstein cows
}

\author{
M. A. Pérez-Cabal ${ }^{* 1}$ and N. Charfeddine \\ *Department of Animal Production, Complutense University of Madrid, 28040 Madrid, Spain \\ †CONAFE, Spanish Holstein Association, 28340 Valdemoro, Spain
}

\section{ABSTRACT}

Data of first-lactation Holstein cows including claw disorders, foot and leg type traits, and structure and capacity type traits were used to study the phenotypic association of conformation and body weight with claw health status. The claw disorders studied were digital and interdigital dermatitis, sole ulcer, white line disease, and an overall claw disorder trait, indicating the presence of any of the 6 claw disorders recorded by the Spanish I-SAP program. Body weight was estimated indirectly with the Von Bertalanffy equation using live weight, which was also estimated from body depth, stature, and chest width. Cows with poor scores for foot and leg traits were more likely to have a claw disorder, with the exception of rear leg rear view and foot and leg composite that did not show any association with the studied disorders. The heavier the cow was, the higher was the probability of having sole ulcer, white line disease, or overall claw disorder trait, but digital and interdigital dermatitis, as an infectious disorder, did not show any association with body weight. Therefore, it is recommended that the preventive trimming routine be improved, which means checking each cow at least once per lactation and trimming if necessary, to achieve balanced weight-bearing for heavier cows and cows with poor feet and leg classification.

Key words: claw disorder, feet and legs, body weight, trigger factor

\section{Short Communication}

Lameness, as an abnormal gait, is one of the main causes of losses in dairy cattle in terms of animal wellbeing and economics of the herd (Enting et al., 1997; Huxley, 2013). Moreover, lameness is mainly due to claw disorders as a result of multifactorial reasons at both cow and herd level, such as the number of lactation or

Received April 19, 2016.

Accepted August 1, 2016

${ }^{1}$ Corresponding author: mapcabal@vet.ucm.es age of the cow, housing type, and herd management conditions (Cook and Nordlund, 2009; Pérez-Cabal and Alenda, 2014; Pérez-Cabal and Charfeddine, 2014). Most authors have reported the phenotypic association of claw health status with locomotion and body condition of the cow, using claw disorders as explanatory variables. For example, Gomez et al. (2015) reported that hoof conformation changed in heifers affected by digital dermatitis (increasing heel height and claw angles, as well as the interdigital cleft), which has been used as a predictor of claw health status before claw disorders become symptomatic. But few authors in their research dealt with claw disorders as a consequence of foot and leg conformation and animal BW. The aim of the present work was to study the conformation of feet and legs and BW as potential trigger factors for claw health of the Spanish dairy cattle.

The claw health information was obtained from the I-SAP program (Claw Health information; in Spanish: Información de Salud Podal), implemented by the Spanish Holstein Association (CONAFE) in Spain since 2012, which is still ongoing. The trimmers periodically visit farms with the objective of checking all the cows of a herd each year, but they also collect data during emergency visits; for more information see Pérez-Cabal and Charfeddine (2015). For this study, we considered the claw health data recorded between 2012 and 2014 . Six claw disorders were recorded as categorical traits: 1 was absence of disorder, 2 was mild diagnosis, and 3 was severe diagnosis. However, only 3 disorders were considered in this study because of the low prevalence of the other disorders: interdigital and digital dermatitis (DE) with a prevalence of $8.58 \%$, sole ulcer (SU) with a prevalence of $16.18 \%$, and white line disease (WL) with a prevalence of $7.20 \%$. We also studied another trait called overall claw disorder (OCD), which indicates the absence or the presence of at least one of the 6 claw disorders; that is, including interdigital hyperplasia, chronical laminitis defined as concave dorsal wall (Egger-Danner et al., 2015), and interdigital phlegmon, not analyzed individually in this study. The score for OCD was the highest of the disorders diagnosed for a cow per lactation. Claw disorders were studied as 
binary responses, such that mild and severe diagnoses were grouped in one class, and only the diagnoses of rear feet were considered.

The conformation traits were routinely recorded by professional classifiers from CONAFE. Six foot and leg traits were considered as explanatory variables for the study of the phenotypic association with claw disorders: foot and leg composite, foot angle, bone structure, rear leg set, rear leg rear view, and locomotion (WHFF, 2014). The classifiers give the locomotion score only if the cow is not diagnosed as a lame cow; otherwise, they wait until the next visit.

A data set with type information and claw disorders of 16,246 primiparous cows were used $(15,287$ for locomotion) for analysis type I (association between each type trait and claw health). The linear type traits were grouped into 3 categories, such that 1 to 3 were low scores, 4 to 6 were intermediate scores, and 7 to 9 were high scores. The foot and leg composite was grouped following the ICAR Recording Guidelines (2014) as follows: fair (less than 75 points), good (from 75 to 79 points), good plus (from 80 to 84 points), and very good (from 85 to 89 points).

Last, we performed what we called analysis type II, where the explanatory variable studied for the presence of claw disorders was BW. However, BW was not recorded on farms and BCS was not available so we had to estimate it by a 3 -step process. First, we obtained a prediction equation of live weight from several conformation traits related to body size; second, we predicted the live weight of the cows with claw health information; and third, we estimated the BW of those cows using the predicted live weight in the Von Bertalanffy equation (Korver et al., 1985). In a previous publication, we estimated live weight using the linear trait size (e.g., Pérez-Cabal et al., 2006). However, since 2004, cow size has not been recorded and we had to use historic information of 139,966 Spanish Holstein cows that were classified from 1986 until 2004 to obtain a reliable prediction equation. We performed a regression analysis using PROC REG with the STEPWISE option (version 9.2, SAS Institute Inc., Cary, NC) such that traits with a $5 \%$ level of significance remained in the final model. The model that best predicted live weight $\left(\mathrm{R}^{2}=0.79\right)$ included stature, body depth, and chest width, as follows:

$$
\begin{aligned}
& \text { LW }=404.93162+16.75626 \times \text { body depth } \\
& +8.06828 \times \text { stature }+8.90758 \times \text { chest width, }
\end{aligned}
$$

where LW is live weight. From this equation we obtained the live weight of 26,685 cows (data set for analysis type II) in first lactation with claw health
Table 1. Summary of prevalence of claw disorders for each analysis and descriptive statistics (mean and SD) of conformation traits and BW

\begin{tabular}{lcc}
\hline Item & $\begin{array}{c}\text { Prevalence in } \\
\text { analysis with } \\
\text { conformation }\end{array}$ & $\begin{array}{c}\text { Prevalence in } \\
\text { analysis } \\
\text { with BW }\end{array}$ \\
\hline Claw disorder ${ }^{1}$ & 6.48 & \\
DE (\%) & 11.49 & 6.46 \\
SU (\%) & 5.18 & 6.65 \\
WL (\%) & 24.90 & 27.95 \\
OCD (\%) & Mean & SD \\
Conformation traits and BW & 77.77 & 3.60 \\
Feet and legs composite & 5.33 & 1.41 \\
Foot angle & 5.61 & 1.40 \\
Bone structure & 5.23 & 1.32 \\
Rear legs set & 4.98 & 1.44 \\
Rear leg rear view & 4.52 & 1.18 \\
Locomotion & 725.35 & 52.97 \\
BW (kg) & \multicolumn{1}{c}{ (kg) } \\
\hline
\end{tabular}

${ }^{1} \mathrm{DE}=$ dermatitis; $\mathrm{SU}=$ sole ulcer; $\mathrm{WL}=$ white line disease $\mathrm{OCD}=$ overall claw disorder.

information and 305-d milk production of the lactation at trimming. The BW was estimated using the Von Bertalanffy equation (Korver et al., 1985) with the predicted live weight, the known age of type classification from the classification records, and the same ratio birth weight-BW and maturity rate used in Pérez-Cabal et al. (2006) for the Spanish Holstein population. For the present analyses, BW was grouped in 3 classes according to the 25th and 75th quantiles such that low weight $(\leq 691 \mathrm{~kg}$ ), intermediate weight (from 691 to $761 \mathrm{~kg}$ ), and high weight $(>761 \mathrm{~kg})$. The statistical summary of traits used in the study is shown in Table 1.

The 2 types of association analyses between the explanatory variables and the response variables related to claw health (DE, SU, WL, and OCD) were carried out using a binary distribution and a probit link function using the PROC GLIMMIX (SAS Institute Inc., Cary, NC). Odds ratios (OR) were calculated showing the probability of DE, SU, WL, and OCD for different levels of foot and leg traits and BW with respect to a reference, which was the most desirable, that is the largest score for all of them, except for rear leg set, which is an intermediate optimum. Odds ratios were significant if the $95 \%$ confidence interval did not include 1 . The linear model fitted to each of the claw disorder traits (CD) mentioned above was

$$
C D_{i j k l}=\eta_{i j k l}+\varepsilon_{i j k l}
$$

where $\eta_{i j k l}$ was a linear predictor, and $\varepsilon_{i j k l}$ was the random error term, such that $\varepsilon \sim N\left(\mathbf{0}, \mathbf{I} \sigma_{\varepsilon}^{2}\right)$ was the joint Gaussian distribution of model residuals $(\varepsilon)$, where $\mathbf{I}$ is an identity matrix and $\sigma_{\varepsilon}^{2}$ is the residual variance. The 
linear model using the probit link was fitted following this scoring rule:

$$
C D_{i j k l}=\left\{\begin{array}{ll}
1(\text { presence }) & \text { if } \mu_{i j k l}>0 \\
0(\text { absence }) & \text { otherwise }
\end{array},\right.
$$

where $\mu_{i j k l}=\eta_{i j k l}+z_{i j k l}$ was a latent variable (i.e., the liability to have a specific claw disorder), and $z_{i j k l}$ were independent and identically distributed standard normal random variables. The probability of an event of any of the claw disorders studied was $P\left(C D=1 \mid \mu_{i j k l}\right)=\Phi\left(\mu_{i j k l}\right)$, where $\Phi($.$) was the standard$ normal cumulative distribution function. The linear predictor was $\eta_{i j k l}=\alpha_{0}+a_{g e}+$ stage $_{j}+H T V_{k}+E V_{l}$, where $\alpha_{0}$ was the overall mean; $E V_{l}$ was each of the explanatory variables at a time $(l=3$ categories for each of the 6 foot and leg conformation traits in analysis type I, and 3 categories for BW in analysis type II); $a g e_{i}$ was the systematic effect of age at calving $(i=331$ categories in analysis type I and 50 levels in analysis type II); stage $e_{j}$ was the systematic effect of stage of lactation at trimming $(j=36$ categories in both analysis type I and II: 0-60, 61-120, 121-180, 181-240, 241-305, and >305 d); HTV $V_{k}$ was the systematic effect of herd-trimmer visit $(k=31,679$ categories in analysis type I and 1,670 categories in analysis type II). In analysis type II, the 305-d milk production corresponding to the lactation at trimming was included as a covariate to avoid confounding the higher milk production of heavier cows, but it was only statistically significant (in addition to BW) for OCD and SU.

Odds ratios for claw disorders depending on the conformation traits are shown in Figure 1. The foot and leg composite trait was not statistically associated with any of the disorders. This composite is, however, a classification to bring together all the linear traits with special emphasis on locomotion, which showed an association with OCD because of the biomechanical stress, as Chapinal et al. (2013) also reported. However, the other linear traits were clearly associated with claw health, with the exception of rear leg rear view, which did not show an association with any of the disorders we studied. As expected, DE was not associated with the morphology of feet and legs, except with the rear leg set, and because of its infectious origin it is more related to the environmental hygienic conditions. However, OCD and WL showed a statistical association with most of the traits. Toussaint Raven (1985) explained that the distribution of BW on each claw of the cow is determined by the position of the hind legs. In our study, intermediate foot angle scores led to cows being $8 \%(\mathrm{OR}=0.92 ; 95 \% \mathrm{CI}=0.86-0.98)$ and $20 \%(\mathrm{OR}=$
$0.80 ; 95 \% \mathrm{CI}=0.72-0.9)$ less likely to have OCD and WL, respectively. Peterse (1986) reported that steep claws had fewer and less serious sole lesions. A high score for foot angle means that cows have a steep angle, which requires less hoof trimming. But our results suggested that extreme steep foot angle might interfere with the proper cushioning effect on the coronary band and could put undue stress on the junction between the wall and the sole of the claw. Intermediate foot angle scores seem more beneficial for claw health, because the weight-bearing is uniform on all the claw surface, either on the sole or on the wall. In fact, trimming requires the adaptation of the dorsal wall length to achieve an adequate sole thickness and to avoid a toe lesion, such as a toe ulcer or a toe necrosis. The recommended toe angle at trimming varies from $45^{\circ}$ to $52^{\circ}$ (Archer et al., 2015), which corresponds to 5 to 7 points as a type score for foot angle. High scores for bone structure in our work were associated with a low probability of WL and OCD. The cows with broad and thick bone structure were $21 \%$ (95\% CI of 1.09-1.35) more likely to have OCD and 49\% (95\% CI of 1.05-1.31) more likely to have WL. Regarding rear leg set, as expected for an intermediate optimum trait, the intermediate scores were the most favorable for a much healthier claw. Vermunt and Greenough (1996) found a negative effect of both extremes on claw health. However, in our study, high scores (i.e., sickled legs) were associated with high odds ratios for $\mathrm{OCD}, \mathrm{DE}$, and $\mathrm{SU}$, whereas low rear leg set scores (straight legs) had no effect on claw health.

Figure 2 shows the odds ratio for the 4 claw disorders depending on the BW. The heavier the cow was, the higher was the probability of having any of the 3 disorders: SU, WL, or OCD. The animal's weight produces a huge stress on the claw, particularly if it is not well balanced over all claws. Our results showed that disorders that affect the corium quality were associated with BW, but an infectious disorder such as DE was not. The OCD trait involves both infectious and metabolic disorders (in our case, WL, SU, and chronic laminitis), and because the latter were more frequent, OCD shows high association with BW. Schöpke et al. (2013) also found that infectious disorders were independent of BW, but contrary to our results they did not find any association between $\mathrm{SU}$ and $\mathrm{BW}$. The metabolic origin of SU, WL, and laminitis (as chronic laminitis shown by a concave dorsal wall) could explain our results because larger cows ended up being high producing cows, with high production demands and high energy requirements, which predispose cows to have more metabolic problems. Even more, the extra ingestion of feed and the extra production of milk are an additional weight for the cow. Gearhart et al. (1990) pointed out that over- 
weight cows may be predisposed to lameness problems due to the increased mechanical stress placed on their musculoskeletal systems. Pregnancy and the growing udder increase the weight and this may alter the animal posture. Unbalanced weight-bearing between the inner and the outer rear claws, such that the weight moves from the wall to the sole of the outer claw, compromises normal horn growth, and the claw become more susceptible to claw disorders. Bergsten (2001) suggested that the relative weight between and within the claws of each foot was more important than the absolute weight. In addition, larger cows lie down less time than smaller and intermediate size cows because they need to spend more time feeding, as Dado and Allen (1994) found. Furthermore, the cubicle size tends to be insufficiently comfortable for these large cows.

\section{Foot angle}

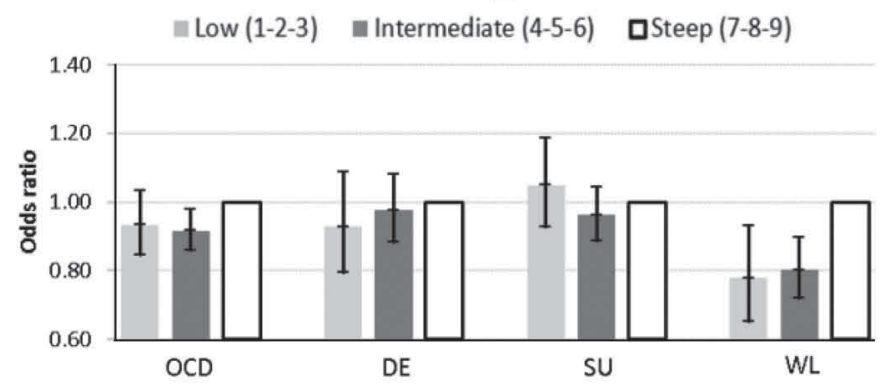

Bone structure

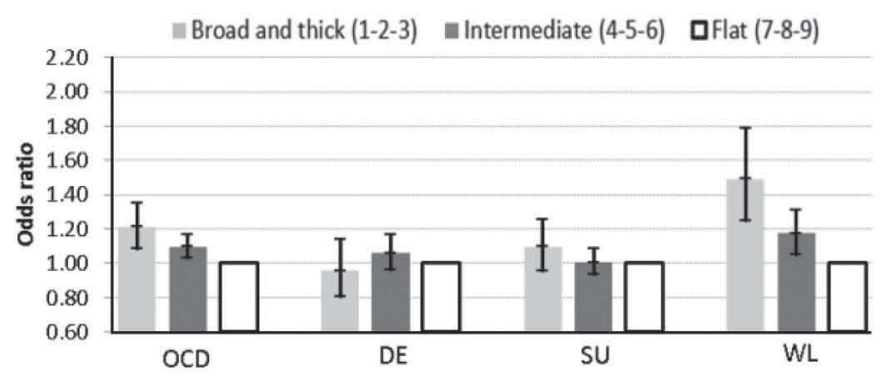

Rear leg rear view

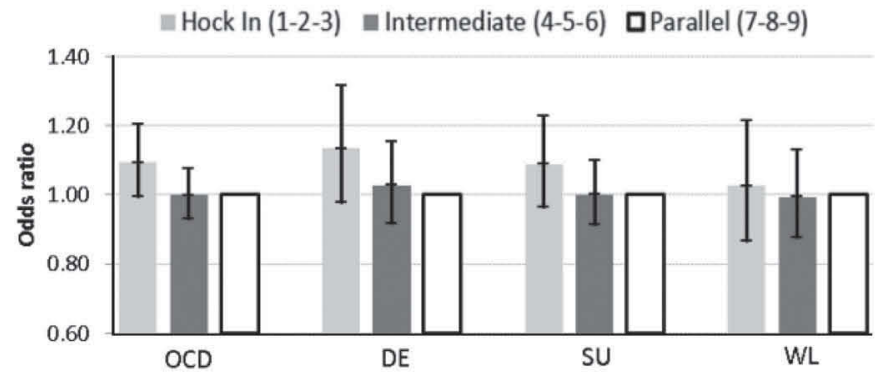

Given that cows with poor locomotion, coarse bone, sickled rear legs set, or heavy weight seemed to be more associated with a high probability of claw disorders, it is strongly recommended to pay more attention to these susceptible cows and to establish a preventive trimming routine for them within a claw health program in every herd.

\section{ACKNOWLEDGMENTS}

The authors thank the Spanish dairy association (CONAFE) for their financial support (grant agreement with Complutense University of Madrid, 4155680 UCM-CONAFE). We also acknowledge Seragro, S.C.G. (A Coruña, Spain), Anka Hoof Care (Navarra, Spain), and all the trimmers involved in the I-SAP program.

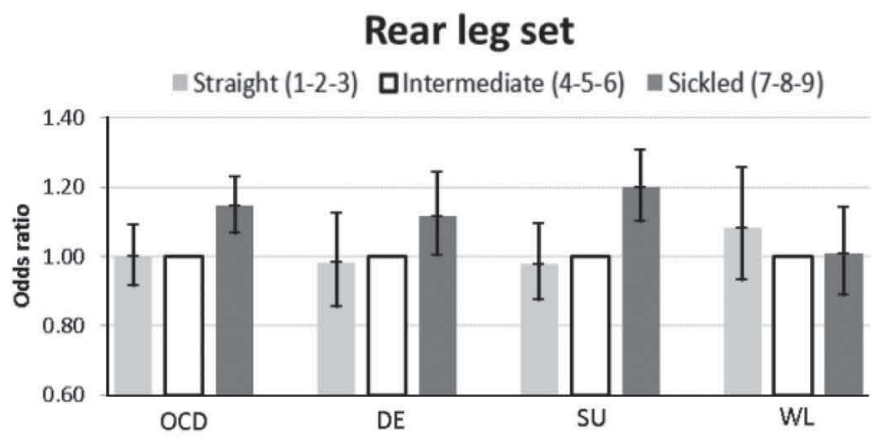

\section{Locomotion}

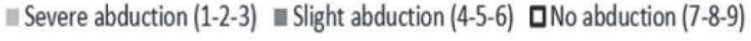

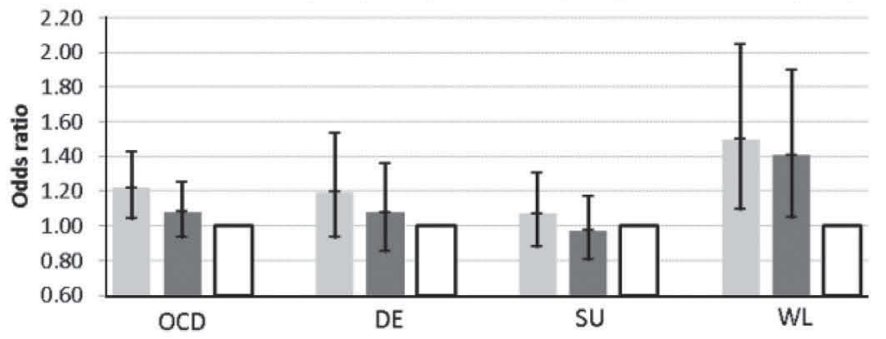

Feet and legs composite

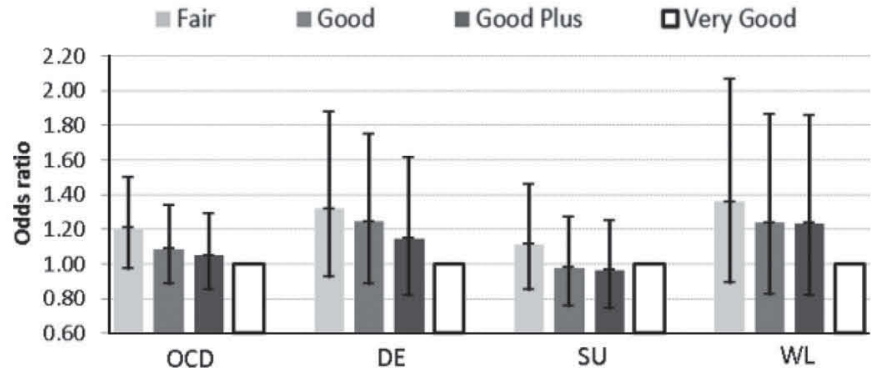

Figure 1. Odds ratios and 95\% confidence intervals for overall claw disorder (OCD), dermatitis (DE), sole ulcer (SU), and white line disease (WL) associated with foot and leg conformation traits. The reference level (odds ratio equals 1) is the preferable category, which is the maximum except for rear leg set. 


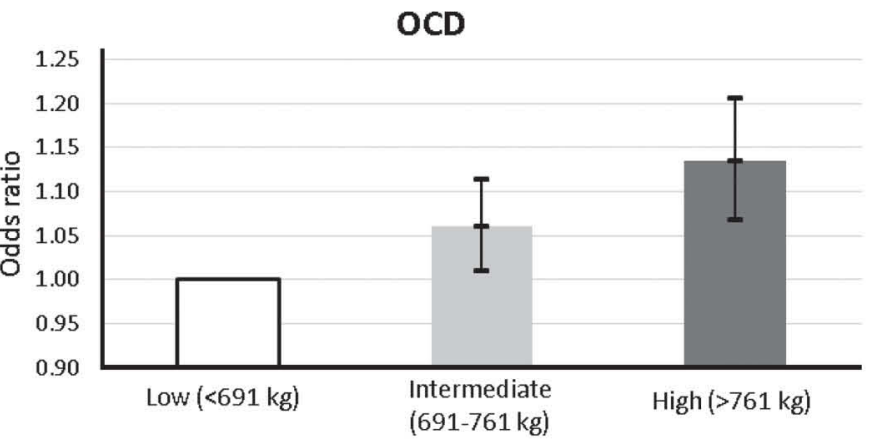

SU

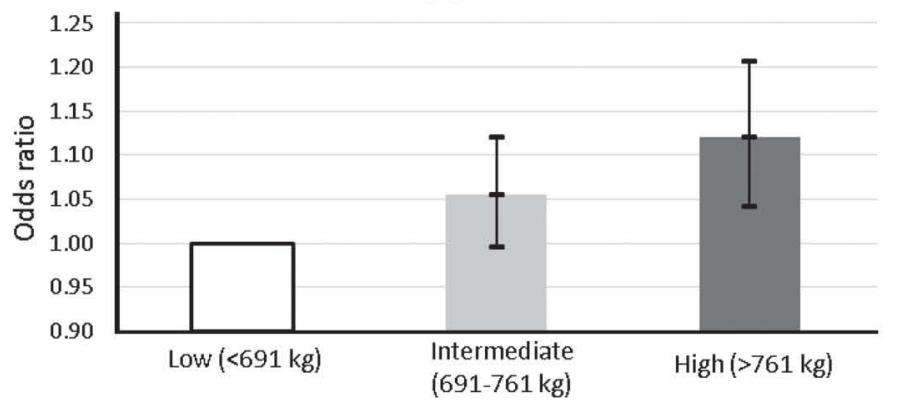

DE

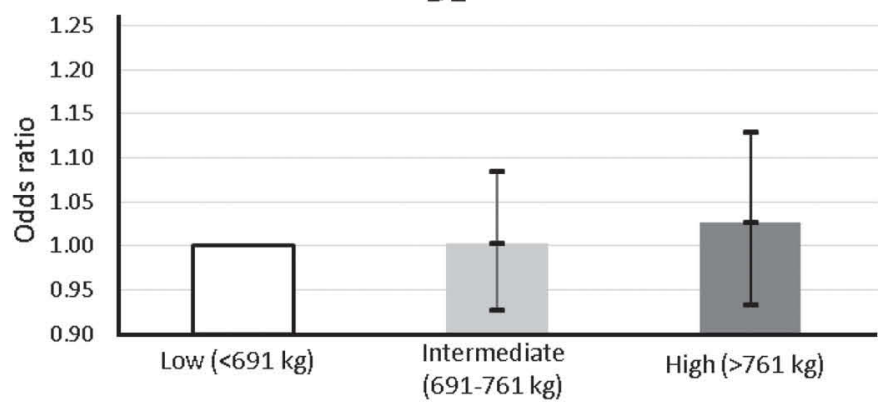

WL

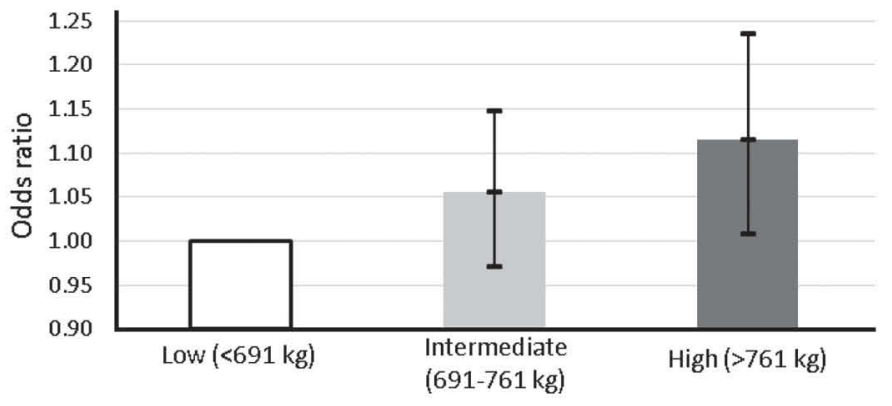

Figure 2. Odds ratios and $95 \%$ confidence intervals for overall claw disorder (OCD), dermatitis (DE), sole ulcer (SU), and white line disease (WL) associated with the BW. The reference level (odds ratio equals 1) is the low weight.

\section{REFERENCES}

Archer, S. C., R. Newsome, H. Dibble, C. J. Sturrock, M. G. G. Chagunda, C. S. Mason, and J. N. Huxley. 2015. Claw length recommendations for dairy cow foot trimming. Vet. Rec. 177:222. http://dx.doi.org/10.1136/vr.103197.

Bergsten, C. 2001. Effects of conformation and management system on hoof and leg diseases and lameness in dairy cows. Vet. Clinics of North America: Food Animal Practice 17:1-23.

Chapinal, N., A. Koeck, A. Sewalem, D. F. Kelton, S. Mason, G. Cramer, and F. Miglior. 2013. Genetic parameters for hoof lesions and their relationship with feet and leg traits in Canadian Holstein cows. J. Dairy Sci. 96:2596-2604.

Cook, N. B., and K. V. Nordlund. 2009. The influence of the environment on dairy cow behavior, claw health and herd lameness dynamics. Vet. J. 179:360-369.

Dado, R. G., and M. S. Allen. 1994. Variation in and relationships among feeding, chewing, and drinking variables for lactating dairy cows. J. Dairy Sci. 77:132-144.

Egger-Danner, C., P. Nielsen, A. Fiedler, K. Müller, T. Fjeldaas, D. Döpfer, V. Daniel, C. Bergsten, G. Cramer, A. M. Christen, K. Stock, G. Thomas, M. Holzhauer, A. Steiner, J. Clarke, N. Capion, N. Charfeddine, E. Pryce, E. Oakes, J. Burgstaller, B. Heringstad, C. Ødegård, and J. Kofler. 2015. ICAR Claw Health Atlas. ICAR, Rome. Accessed Jul. 29, 2016. http://www.icar.org/documents/ icar_claw_health_atlas.pdf.

Enting, H., D. Kooij, A. A. Dijkhuizen, R. B. M. Huirne, and E. N. Noordhuizen-Stassen. 1997. Economic losses due to clinical lameness in dairy cattle. Livest. Prod. Sci. 49:259-267.

Gearhart, M. A., C. R. Curtis, H. N. Erb, R. D. Smith, C. J. Sniffen, L. E. Chase, and M. D. Cooper. 1990. Relationship of changes in condition score to cow health in Holsteins. J. Dairy Sci. 73:31323140 .

Gomez, A., N. B. Cook, J. Rieman, K. A. Dunbar, K. E. Cooley, M. T. Socha. And, and D. Döpfer. 2015. The effect of digital dermatitis on hoof conformation. J. Dairy Sci. 98:927-936.
Huxley, J. N. 2013. Impact of lameness and claw lesions in cows on health and production. Livest. Sci. 156:64-70.

ICAR Recording Guidelines. 2014. International agreement of recording practices. Accessed Jan. 14, 2016. http://www.icar.org/index. $\mathrm{php} /$ publications-technical-materials/recording-guidelines/.

Korver, S., J. A. M. Van Arendonk, and W. J. Koops. 1985. A function for live weight change between two calvings in dairy cattle. Anim. Prod. 40:233-241.

Pérez-Cabal, M. A., and R. Alenda. 2014. Clinical lameness and risk factors in a Spanish Holstein population. Livest. Sci. 164:168-174.

Pérez-Cabal, M. A., and N. Charfeddine. 2014. Claw lesions and risk factors in Spanish dairy cows. Poster \#823 in Proceedings of 10th WCGALP, August 17-22, Vancouver, Canada. https://asas.org/ wcgalp-proceedings/species-breeding-dairy-cattle- $\% 28$ posters $\% 29$.

Pérez-Cabal, M. A., and N. Charfeddine. 2015. Models for genetic evaluations of claw health traits in Spanish dairy cattle. J. Dairy Sci. 98:8186-8194.

Pérez-Cabal, M. A., R. González Santillana, and R. Alenda. 2006. Mature body weight and profit selection in Spanish dairy cattle. Livest. Sci. 99:257-266.

Peterse, D. J. 1986. Claw measurements as parameters for claw quality in dairy cattle. Pages 87-91 in Proceedings of the Vth International Symposium on Disorders of the Ruminant Digit, Dublin.

Schöpke, K., S. Weidling, R. Pijl, and H. H. Swalve. 2013. Relationships between bovine hoof disorders, body condition traits, and test-day yields. J. Dairy Sci. 96:679-689.

Toussaint Raven, E. 1985. Structure and functions. Pages 27-34 in Cattle Footcare and Claw Trimming. Farming Press Books, Ipswich, UK.

Vermunt, J. J., and P. R. Greenough. 1996. Hock angles of dairy heifers in two management systems. Br. Vet. J. 152:237-242.

WHFF (World Holstein Friesian Federation). 2014. 2014 Type Harmonization report and recommendations. Accessed May 27, 2016. http://www.whff.info/documentation/documents/2014TypeHarm onisationReportandRecommendations.pdf. 